\title{
Socioeconomic Determinants of Malaria Prevention Options Adoption of Households in the North West Region of Cameroon
} \author{
Omarine Nlinwe Nfor ${ }^{3}$ \\ ${ }^{1}$ Faculty of Economics and Management Sciences, The University of Bamenda, Bambili, Cameroon \\ ${ }^{2}$ Higher Institute of Commerce and Management, The University of Bamenda, Bambili, Cameroon \\ ${ }^{3}$ Faculty of Health Sciences, The University of Bamenda, Bambili, Cameroon
}

Ivan Mboambogoh Yakum ${ }^{1,2}$, Godfrey Forgha Njimanted ${ }^{1,2}$, Andrew Wujung Vukenkeng ${ }^{1,2}$,

\section{Email address:}

ivanyakum@yahoo.com (I. M. Yakum), unicalub@yahoo.com (G. F. Njimanted), vukengwujung@yahoo.com (A. W. Vukenkeng), omarinenlinwe@yahoo.ca (O. N. Nfor)

\section{To cite this article:}

Ivan Mboambogoh Yakum, Godfrey Forgha Njimanted, Andrew Wujung Vukenkeng, Omarine Nlinwe Nfor. Socioeconomic Determinants of Malaria Prevention Options Adoption of Households in the North West Region of Cameroon. International Journal of Health Economics and Policy. Vol. 5, No. 2, 2020, pp. 15-30. doi: 10.11648/j.hep.20200502.11

Received: May 19, 2020; Accepted: June 1, 2020; Published: July 23, 2020

\begin{abstract}
Despite its simple and perceived affordable prevention methods, malaria has over time remained the main killer disease in Africa, Sub Sahara Africa, Cameroon and the North West Region in Particular. It is from the above backdrop that this study uses quantitative approach to examine the socioeconomic determinants of malaria prevention options adoption by households in the North West Region of Cameroon. Thus, data was collected from 400 households purposively selected among the top ten health districts with high prevalence of malaria in the North West Region of Cameroon. The study used both Ordinary Least Square, Poisson and Ordered Logit Regression techniques to capture the socioeconomic determinants of malaria prevention behaviour of households. These different methodologies were used to check the robustness of the results as methodology changes. The findings reveal that community based malaria prevalence, knowledge of malaria signs, knowledge of malaria cause, age of household heads, marital status of household heads, household size, cost of malaria prevention, household monthly income, education and employment status of the household head are all socioeconomic factors that determine malaria prevention options adopted by households in the North West Region. Based on the findings, the study strongly recommends further sensitization campaigns; creation of community-based malaria control committees; sponsored media programs; household empowerment programs, free distribution of Insecticide Treated Bed Nets, the use of holistic rather than individualistic malaria prevention strategies, among others as specific policy measures that can health achieve the much desired goal of eradicating malaria in the North West Region and Cameroon as a whole.
\end{abstract}

Keywords: Malaria Prevention Behaviour, Socioeconomic Determinants, Ordinary Least Square, Poisson, Ordered Logit, North West Region, Cameroon

\section{Introduction}

Of all diseases, malaria is perhaps the one with the most elusive interplay with human history. It has long affected human beings, and has left its mark on modern populations. The disease acted as a barrier to European colonialism and rendered many areas of the world, especially in Africa, largely unproductive. Malaria influenced, and its incidence has been in turn influenced by human activities and practices from time immemorial. It is perhaps the most ecologically sensitive of all human diseases. [1].

The impact of malaria on the overall economic growth cannot be undermined as [2] predict a complete economic collapse within 3 generations if nothing is done to combat the epidemic in South Africa and other overwhelming evidences especially on the effect on per capita income of malaria reveal that countries with intensive malaria grew $1.3 \%$ less per person per year [3]. Estimates show that a $10 \%$ reduction 
in malaria was associated with $0.3 \%$ higher growth and growth between 1965 and 1990 for countries with malaria has been $0.4 \%$ per annum compared to average growth for other countries of $2.3 \%$ [3] and had Africa had no malaria over the last four decades, its annual growth rate would have been $1.25 \%$ higher than it actually [4].

Cameroon, fondly known as "Africa in miniature", presents diversified strata of malaria transmission along with the corresponding parasites and vectors as malaria continues to be endemic and the first major cause of morbidity and mortality right from the colonial period as plasmodic index stood at about $35 \%$ in the $50 \mathrm{~s}$ [5]. Based on the above, large scale malaria vector control projects focused on house spraying were implemented in Southern and Northern parts of Cameroon in line with malaria eradication concept. Within the malaria control program initiated in 1953 which went operational in 1956, both DDT and dieldrin were used in the South, while in the North only DDT was used to avoid dieldrin resistance observed in 1956 in the South [5-7]. From a strictly operational point of view, the campaign was considered as a success but after two years, it was noticed that plasmodic index remained still around the same value of $35 \%$ and the programme stopped. It was thus stated that according to available techniques it was not possible to reach the ultimate goal of eradication and thus the vector control was then stopped for a while [5].

In the eighties, Primary Health Care was promoted and malaria control shifted from vector to parasite control with vector control remaining as a prevention method. But chemoresistance of the parasite appeared and quickly spread, at different levels, across the country which gave rise to a new emphasis on vector control thanks to the newly developed technique of insecticide treated mosquito nets (ITNs). It thus clearly appeared that ITNs were very successful in sharply reducing malaria transmission and morbidity. But its promotion was limited by the current poor use of mosquito nets [5].

The year 1995 was a turning point in the history of malaria control marked by the drafting of the first National Malaria Control Programme (NMCP) document in line with the 1992 Ministerial conference that held in Amsterdam. This was followed in 1997 by the declaration of the national policy for the control of malaria as approved by Cameroon Government. In December 1998, the Central Technical Group for the Malaria Control was created. The President of the Republic was personally committed to this new drive towards malaria control activities through the letter he sent to the WHO Director General on the 28th April 1999. Following the signing of the Abuja Declaration on the 24th of April 2000 by the African Heads of States, its launching in Cameroon on the 25th July 2000 by the Minister of Public Health and its concretised in 2002 with a National Malaria Control Strategy Plan gave rise to what prevails today [8, 9]. The implementation of this plan is financed by multiple sources: State, Global Fund to fight HIV/Aids, Tuberculosis and Malaria (GFATM), World Health Organisation (WHO), United Nations International Children Emergency Fund
(UNICEF) and Bill and Melinda Gates Foundation. Households contribute the largest share of financing through malaria prevention and home based care [9].

The NMCP was later restructured to make it more operational and in that light, the 2007-2010 strategy plan aims at contributing towards the achievement of MDG 6 through prevention, improving case management, communication behaviour change in favour of malaria, training and operational research, capacity building and partnership development [5].

At present, there is United States Agency for International Development (USAID) and Centers for Disease Control and Prevention (CDC) present in Cameroon all fighting malaria while in February 2015, the Global Fund and Government of Cameroon signed a malaria grant agreement worth 77 million Euros. The grant has been used to fund distribution of 15.8 million ITNs, including a mass distribution campaign that was conducted in 2016. Cameroon's National Strategic Plan (NSP) for malaria control which covers the period 2014-2018 and is the fourth iteration of a national strategy was developed based on an external mid-term review conducted in 2013 (at the mid-point of the previous 2011-2015 strategy). The goal of the NSP 2014-2018 was to contribute to improving the health of Cameroonians by reducing the health and socioeconomic burden of malaria. The objective was to reduce malaria morbidity and mortality by $75 \%$ from 2000 levels by 2018 [10].

Despite all the above efforts malaria still remained perennial in Cameroon since according to the 2011 Malaria Indicator Survey, the average prevalence of parasitemia in children under the age of five was 33.3\%. Also, NMCP's annual report in 2015 suspected malaria caused $30 \%$ of all medical consultations; $21 \%$ of all cause visits resulted in a diagnosis of laboratory-confirmed malaria. In health facilities, $19 \%$ of deaths were attributed to malaria, and $48 \%$ of all hospital admissions were due to suspicion of severe malaria [11].

In the North West region of Cameroon, morbidity due to malaria as a percentage of total morbidity was $19 \%$ in 2015 and $20 \%$ in 2016 and this is a little wonder given that there was free Insecticides Treated Mosquito Nets (ITNs) distribution in the North West Region in 2016 [12]. Findings reveal that the incidence of malaria is higher in the rural areas than the urban areas. While the regional average of malaria incidence for the North West Region was 19\% and $20 \%$ of total mobidity in 2015 and 2016 respectively, the leading districts were rural health districts of Ako and Njikwa with $60 \%$ and $44 \%$ \& of total mobidity in 2015 and $55 \%$ and $47 \%$ \& of total mobidity in 2016 respectively $[12,13]$.

The above analyses reveal that policies have come and gone but malaria remains with very insignificant change in the prevalence resulting from policy and many people still sick and die of malaria in Cameroon and in the North West Region in particular despite its preventable and curable nature. The problem is that malaria remains a major threat to welfare and consequently life in the Cameroon in general and in the North West Region in particular despite the fact that it 
is preventable through avoiding mosquito bites mostly by the use of ITNs most often freely distributed, use of mosquito repellents (both modern and local) which are believed to be very affordable and other practices like creating better drainage system and clearing the surroundings among others accompanied by the numerous policies put in place by the government and foreign bodies to ameliorate the situation and malaria is curable compared to other diseases such as HIV/AIDS which are incurable.

Globally, the challenges of curbing the prevalence of malaria are in three folds: Biomedically, blames are layed on the fact that malaria parasite continuously develop drug resistance when ever new drugs are introduced and also wrong diagnises, wrong prescriptions meaning that preventive measures and practices can do much good than curative measures [14-16].

Sociologically, low level of acceptance and use of the current malaria prevention options (especially the use of ITNs), low level of awareness of the available intervention possibilities, level of formal education and other sociodemorgraphic factors such as age, marital status, gender were acused to be the main factors posing challenges to malaria eradication efforts [17-22].

Economically, lack of availability of Health Economists to greatly increase the number of economic analyses of malaria is a major barrier given that health economics is relatively a new field of study and of all the disciplines required for high quality research on malaria, economists are probably most in short supply. Moreover, economists attracted into health are more likely to work on broad health service issues rather than on specific diseases such as malaria; and malaria research groups often experience difficulties in recruiting economists to join them [23].

It is based on the above precarious situation that this study is designed to look at the socioeconomic determinants of malaria prevention options adoption among households in the North West Region of Cameroon.

\section{Literature Review}

Improved understanding of the factors that influence malaria prevention options adoption by households is necessary in order to enhance the effectiveness of current malaria control strategies. Several studies have been conducted and a synthesis of these studies is necessary to present what is already done and observe what is yet to be done.

The study [22] Examines the role of gender in malaria prevention, examining adoption behaviour between male and female headed households in Kenya. The study uses a recent baseline cross-section survey data collected from 2718 households in parts of western and eastern Kenya. Two separate models were estimated for male- and female-headed households to determine if the drivers of adoption differ between the two categories of households. The findings from the study show that: the number of malaria prevention options adopted by both male and female headed households is significantly increased by access to public health information, residing in villages with higher experience of malaria prevention, knowing cause and transmission of malaria. On the other hand, formal education of the household head and livestock units owned exhibited a positive and significant effect on adoption among maleheaded households, but no effect among female-headed households.

[24] In their study aimed at investigating factors that influence malaria prevention and control practices among pregnant women residing in Chorkor and Korle-Gonno in Accra, Ghana used 120 pregnant women between ages 18-49, randomly recruited during antenatal sessions at a maternity facility in Accra, as participants for the study. An intervieweradministered questionnaire was used to collect data, which were analysed using SPSS version 16.0. It was found that in Chorkor and Korle-Gonno, $57.4 \%$ and $42.6 \%$ participants respectively reported having been infected with malaria during their current pregnancy. There was no significant relationship between religious beliefs of participants and their malaria prevention and control practices. However, there was a significant relationship between malaria prevention and control practices of participants and their income earning and employment statuses. With the exception of ethnicity, other socio-cultural conditions had a significant relationship with malaria prevention and control practices of the participants. The findings suggest the need to consider and integrate factors, such as poverty and poor living conditions in malaria prevention and control strategies.

The study [25] Examined factors which influence the use of different types of malaria prevention methods among pregnant women in Kenya. Using the 2008-09 Kenya Demographic and Health survey. Pregnant women aged 1549 years were included (622 women). They employed bivariate and multivariate logistic regression analysis and revealed that age, malaria risk areas, religion, education and income influenced ITN usage, whereas only age, malaria risk areas and marital status were found to influence Intermittent Preventive Therapy (IPTP) uptake.

The study [26] Used data from the Demographic Health Survey for Tanzania HIV/AIDs and the Malaria Indicator Survey 2011-2012 in a cross-sectional design guided by the health belief model in a Logistic regression to examine the association between preventive treatment seeking behaviour and SES, malaria media exposure, knowledge of malaria signs and symptoms, perceived seriousness of malaria, and knowledge of malaria preventive measures. After controlling for transportation, family responsibility and age, significant associations were found between SES, malaria media exposure, knowledge of malaria signs and symptom, perceived seriousness of malaria, knowledge of malaria preventive measures, and treatment-seeking behaviour. This study contributes to positive social change by helping design and implement policies and programs to improve the knowledge of Tanzanian pregnant women about the risk of malaria infection and the benefits of preventive treatments.

[27] Aimed at investigating factors that influence malaria 
prevention among women of reproductive age in line with the National Malaria Control objectives using descriptive, cross-sectional study design and cluster sampling technique to recruit study participants. Respondents had 'correct' knowledge of malaria if they knew the cause and symptoms of malaria. Otherwise is classified as 'incorrect'. The study reveals that most respondents, $89 \%$ had good knowledge of malaria. Their educational level was significantly associated with this knowledge. There were, however, some myths and misconceptions about malaria. Of $390(49.3 \%)$ that owned insecticide treated bed nets (ITNs), only 59 (18.2\%) used them consistently, while only $31(50 \%)$ of the pregnant women received intermittent preventive treatment (IPTp). Malaria knowledge, ITNs ownership and female education were not significantly associated with ITN and IPTp usage. Married women had 3 times higher odds of ITN usage than the unmarried, and women with children had 2 times higher odds of usage than those without. The study concluded that the use of malaria prevention measures among women of reproductive age is still sub-optimal.

In their study aimed at enhancing malaria prevention in Cameroon through community participation using an indepth [28] reviewed malaria prevention in Cameroon and proposed community based context-specific complementary interventions strategies that will promote community participation in prevention and mitigation of the effects of poverty towards achievement of the sustainable development goals targets for malaria. The study involved an in-depth review of secondary data from electronic and non-electronic documents. They concluded that the current measures alone are insufficient. And therefore, a combination of multiple delivery strategies using an integrated community-based approach is likely to be more effective in breaking the transmission cycle than single programme interventions. Concurrent implementation of community mobilisation through social groups and Village Development Committees, education on house screening, training of mothers and caregivers and health promotion through environmental management were recommended as the best and most feasible strategies.

In their study, [13] examined the role of Household income, family size, gender and age of household head, educational level of the household head, knowledge on signs, symptoms, and prevention of malaria among rural households in the North West Region of Cameroon using data collected from 6341 households selected from ten rural health districts with the highest malaria prevalence in the North West Region. Data were analyzed using ordered logit regression and the findings of this study reveal the significant ability of; gender, age, marital status and educational attainments of household heads; household per capita income; household size; knowledge on malaria prevention in predicting households ' malaria prevention seeking behaviours in the rural areas of the North West Region of Cameroon. There was also evidence of knowledge gap on the signs, causes, and prevention of malaria.

Human behaviour much of which is inherently influenced by social, cultural, economic, and political factors is clearly related to health, including the risk for infectious diseases like malaria, HIV/AIDS, Tuberculosis among others. Whether it is intentional or not, human behaviour affects health-promoting and disease-preventing activities, in some instances increasing risk and in others reducing it [19].

According to [29] human groups have often unintentionally facilitated the spread of infectious diseases through culturally coded patterns of behaviour or through changes in the crucial relationship among infectious disease agents, their human and animal hosts, and the environments in which the host and agent interaction takes place. Beyond human behaviour as such, prevalent sociocultural factors including political and economic parameters also contribute to determining human's behaviour, and thus must be seen as predictors of health and disease patterns. Although people's behaviour may increase malaria risk, such behaviour to be changed is relatively difficult because they often are tied to considerable benefits in areas quite distinct from health as [30] so aptly noted that the principal reason why people do not accept new kinds of health behaviour is that the behaviour being advocated is inconvenient, produces unwanted side-effects, or does not give visible results. Thus, it is hardly for reasons of absence of knowledge for better option but rather their reasoning and rationality is meaningful only to them only within the realities and limitations of their local circumstances.

The physical environment, and people's proximity and exposure to vectors or parasites, including microbiological and parasitological factors, are clearly essential for transmission of infection and constitute necessary and immediate risk factors. Certain sociocultural factors, such as poverty and social disenfranchisement, may place people at continuous risk of malaria infection and may make the affliction from infectious and other diseases inevitable [31, 32].

[29] Talk about proximate cause versus the ultimate cause of political and economic inequality. They suggest that although the presence of (proximate) microbiological risk factors is essential, it is not sufficient, since the ultimate causation is tied to socioeconomic factors, in particular, to inequality. This point is established as well by [32]. With the advent of social epidemiology and medical anthropology in the 1950s and 1960s, represented by such publications as [33] Health, Culture and Community and [34] Health and Human Behaviour: Areas of Interest Common to the Social and Medical Sciences, there was a shift in twentieth-century thinking about sociocultural factors as being complementary to bacteriological ones. With the increase of such literature since then, any public health effort would be delinquent and short sighted if it did not pay significant attention to how behavioural and social factors contribute to risk for and prevention of malaria infection.

The interrelationship between infectious disease and sociocultural characteristics is by now well established, although not fully accepted within international public health circles. In the current effort to mount an effective malaria control campaign, the connection needs to be re-emphasized 
and re-substantiated. To the extent that contemporary malaria control programs deviate little from their early design, and that too many studies still conclude that sociocultural variables should have been taken into account at the program's onset, the redundancy in recommendations for program design is apparently necessary because failure to deal even relatively superficially with the behavioural dimension squanders the technical sophistication and competence of mosquito control technology and the prophylaxis and chemotherapy of plasmodial infections. [35] There has been little written about social factors in the modern resurgence of malaria. This is because the focus of public health, and malariology in particular, has been narrowly fixed on the parasite and the mosquito vector.

The bigger picture has been neglected - namely that increased rates of malaria morbidity, although directly influenced by changes in the parasite and vector, are more directly caused by human behaviours. Those behaviours are both related to individual culturally coded patterns and larger-scale sociological phenomena including the politicaleconomic level.

The bulk of literature reveals that studies have been conducted in other parts of world and even in some parts of Africa which are related even though not perfectly identical to this study such as [22] in Kenya, [36], in Anambra State, South Eastern Nigeria; [37] in Nigeria among others but to the best of our knowledge little of such studies has been conducted in Cameroon as a whole and in the North West Region, One of such studies have been conducted by [13] but it focused only in the rural areas while this current study cuts across both rural and urban areas to see whether such behaviours differ between rural and urban areas of the region. Even with that, the methodology employed in this study is slightly more intensive that that used in the later as multiple techniques were used.

More so, few studies that analyses the economics of malaria prevention and control quite often focus on the direct cost of the prevention or treatment options adopted neglected the indirect cost of work, productivity and income loss due to poor health or caring for a sick person and other cost such as transportation cost to aquire such malaria prevention and treatment services $[15,38]$.

\section{Analytical Methodology}

The study area involves ten health districts in the North West Region of Cameroon with having an estimated population of 824514 found in about 137419 households. This study focused at the household rather than individual level because malaria prevention options adopted hardly vary within a household since it is the household head that usually take such major decisions; the reason why the household head was most preferred in the research. From the total population 400 households were purposively selected involving both rural and urban households and questionnaires distributed based on the various health districts' quarter of population to the total population of the sample area as follows.

Table 1. Distribution of the Sample Size across the Health Districts.

\begin{tabular}{|c|c|c|c|c|c|c|}
\hline Health District & Population 2016 & $\begin{array}{l}2016 \text { Malaria } \\
\text { Prevalence }\end{array}$ & Rank & $\begin{array}{l}\text { Number of Household } \\
\text { (Ave HHsize=6) }\end{array}$ & $\begin{array}{l}\text { \% of District } \\
\text { HH to Total }\end{array}$ & Sample \\
\hline $\mathrm{AKO}$ & 46795 & $55 \%$ & 1 & 7799 & 5.7 & 22.8 \\
\hline NJIKWA & 19096 & $47 \%$ & 2 & 3183 & 2.3 & 9.2 \\
\hline WUM & 129401 & $46 \%$ & 3 & 21567 & 15.7 & 62.8 \\
\hline SANTA & 74200 & $39 \%$ & 4 & 12367 & 9 & 36 \\
\hline BATIBO & 86639 & $36 \%$ & 5 & 14440 & 10.4 & 41.6 \\
\hline BENAKUMA & 57674 & $35 \%$ & 6 & 9612 & 7 & 28 \\
\hline NWA & 73084 & $34 \%$ & 8 & 12181 & 8.9 & 35.6 \\
\hline NDOP & 215084 & $33 \%$ & 9 & 35847 & 26.1 & 104.4 \\
\hline BAFUT & 66673 & $33 \%$ & 10 & 11112 & 8.1 & 32.4 \\
\hline Total & 824514 & & & 137419 & 100 & 400 \\
\hline
\end{tabular}

Source: Prepared by Authors using statistics from [12, 13].

The choice of the sample size was guided by [39] formula for representative sample and the research designed employed was exploratory survey research. The theoretical underpin of this study follows a basic concept of utility maximization and household production of health. This framework starts with the modeling of the selection of malaria prevention option (s), owing to the fact that the household is at a malaria risk zone given the specific household characteristics and quality of the prevention option (s). The formulated model being of discrete choice, so the estimates are for the probability that a household selects given malaria preventive option (s) given the specific features of the households such as income, household size, gender of household head and knowledge about the malaria prevention among others and the quality of the option. In that respect, the study assumes that households make rational decisions regarding malaria prevention, and thus choose malaria prevention practices that maximize their expected net benefits. Thus households decide to adopt a given malaria prevention practice (s) $\mathrm{j}$ if its utility is higher than for all other choices.

We then estimate a behavioural model of malaria prevention demand. Demand in this context is defined as the probability of choosing different types of malaria prevention practices in a malaria risk area, given the relevant characteristics of the individual and household. This model 
adopted and modified from the work of [40, 13] as was summarised by [41] following the work of [42] formulates the utility that a person derives from choosing a particular malaria prevention option, that is,

$$
Y j=\mathrm{f}\left(X_{i}, Z_{j}\right)+U
$$

From equation (1), "Y" is the utility derived from choosing malaria preventive option " $\mathrm{j}$ ", which is a function of socioeconomic characteristics of the household $\left(\mathrm{X}_{\mathrm{i}}\right)$ which is constant with discrete choice and choice specific attributes $\left(Z_{j}\right)$ varying across the discrete choices. Thus, $\mathrm{Zj}$ is quality of preventive option ( $\mathrm{s})$. $\mathrm{U}$ is the error term. This specification also ties with other studies such as [22] among rural households in Kenya and [13] among rural households in the North West region of Cameroon but methodologically, both Ordinary Least Square, Poisson and Ordered Logit regression techniques as opposed to only poisson used by [22] in Kenya and Ordered Logit used by [13] in Rural areas of North West Region of Cameroon and this study also differ from [13] since both used the same study area but the current study include both rural and urban areas of the chosen health disticts while the former considered only rural parts of the selected health districts. The use of the multiple techniques is to check robustness consistency of results across the different methods.

Earlier studies handled prevention options as ordered categorical variables based on which scales were attributed while other used individual binary choice models. And from the recommendations of [22], there is likelihood of inefficiency since households most of the times make simultaneous choices.

[43] used a abinomial transformation of the count ordered variables which is still highly subjective. The dependent variable may be subject to measurement errors and partial or stepwise adoptions many not be captured a binary options and hence count dependent variable could be more reliable [22].

The current study adopt this approach on the basis of which the Ordinary Least Square and Poisson regression analyses were used to analyse the model. This study however, went further to attribute weights to the different malaria prevention strategies since some options are more individualistic while others are more holistic. The dependent variable was thus, categorised and ordered based on the scope of coverage on the basis of which Ordered Logit regression analysis was conducted. Suppose the process is modelled in Equation (2) as

$$
\begin{gathered}
y^{*}=\beta_{i} X_{i}+\mathcal{E} . \\
P R E V=f(C B M P, K N O W, S E X, A G E, M S, H H S, C O S T, I N C, E D U, E M P, T P R) .
\end{gathered}
$$

$\mu_{\mathrm{i}}$ represents endpoints of the observable categories. This permits the use of Ordered Logit regression analysis with the use of the observations on $y$ which are a form of censored data on $y^{*}$ that fit the vector of $\beta_{i}$ as estimated parameters.

The ordered logit specification for an ordinal response $Y i$ with $m$ categories presents a set of $\mathrm{m}-1$ results with the cumulative probabilities gmi $=\operatorname{Pr}(\mathrm{Yi} \leq \mathrm{ym} \mid \mathrm{xi})$ are related to a linear predictor $\beta_{\mathrm{i}} \mathrm{X}_{\mathrm{i}}+\varepsilon$ through the logit function:

$$
\log i t\left(g_{m i} /\left(1-g_{m i}\right)\right)=\alpha_{m}-\beta_{i} x_{i} ; \mathrm{m}=1,2,3, \ldots \mathrm{m}-1
$$

In sum, this study measured the dependent variable (malaria prevention options adopted) in two ways. in the first place, a count number of malaria prevention options adopted was used while in the second place a weighted type of malaria prevention options was used, with weight attributed based on the scope of coverage of the malaria prevention options adopted. The prevention options used in this study were classified as; no option adopted given the weight 0 , individual prevention or preventive treatments (Taking antimalaria or Prophylactic drugs) given the weight 0.17 , preventing mosquito bites (Closing doors and windows, repellents use, use of ITNs) weighted 0.33 and mosquitoes eradication measures (clear buses, Good drainage system, insects sprays use) weighted 0.5. Where the first set (personal prevention) are of a narrow scope and individualistic in nature prevention of mosquito bites prevents beyond individual level but can effectively control only within a house and Mosquitoes eradication measures are more holistic since it can prevent malaria from both individual home and community levels.

Model 4 is the functional models that shows the effect of socioeconomic factors on malaria prevention options adopted.

The empirical model is specified as equation (5);

$$
P R E V=a_{0}+a_{1}^{C B M P}+a_{2} K N O W+a_{3}^{S E X}+a_{4}^{A G E+}+a_{5}^{M S+} a_{6}^{H H S+}+a_{7} C O S T+a_{8}^{I N C+} a_{9}^{E D U}+a_{10}{ }^{E M P}+a_{11} \text { TPR+U }
$$




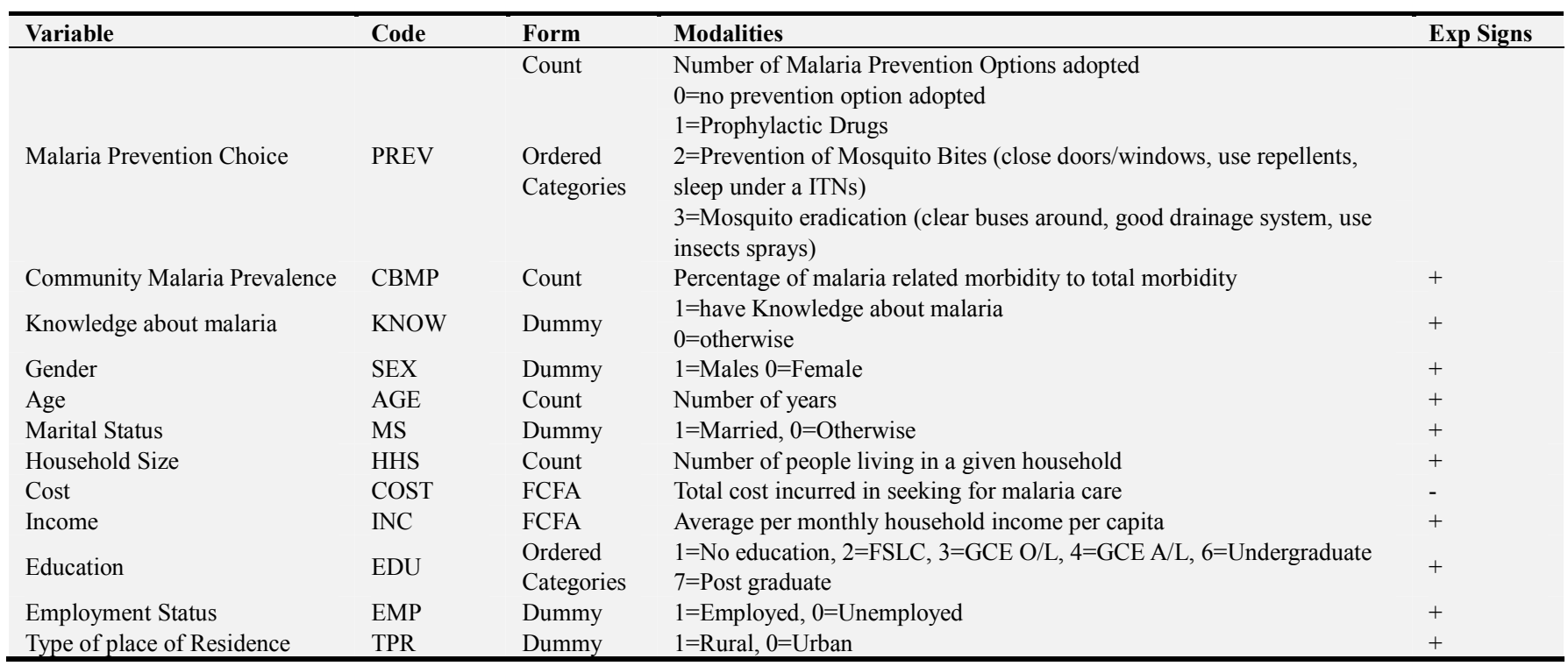

Source: Author, (2019).

\section{Findings and Interpretation of Findings}

Table 3. Demographic Information of Respondents.

\begin{tabular}{|c|c|c|c|}
\hline Demographic Factor & Modalities & Frequency & Percent \\
\hline \multirow{2}{*}{ Gender } & Male & 216 & 54.0 \\
\hline & Female & 184 & 46.0 \\
\hline \multirow{5}{*}{ Age Group } & $<20$ Years & 64 & 16 \\
\hline & 20-30 Years & 178 & 44.5 \\
\hline & $31-40$ Years & 86 & 21.5 \\
\hline & 41-50 Years & 33 & 8.25 \\
\hline & $>50$ Years & 39 & 9.75 \\
\hline \multirow{5}{*}{ Occupation of Respondents } & Farming & 70 & 17.5 \\
\hline & Business & 116 & 29.0 \\
\hline & Civil Service & 82 & 20.5 \\
\hline & Student & 81 & 20.3 \\
\hline & Others & 51 & 12.8 \\
\hline \multirow{2}{*}{ Type of Place of Residence } & Rural & 176 & 44.0 \\
\hline & Urban & 224 & 56.0 \\
\hline \multirow[t]{2}{*}{ Highest Educational Attainment } & Secondary & 171 & 42.75 \\
\hline & Tertiary & 153 & 38.25 \\
\hline \multirow{2}{*}{ Marital Status } & Married & 261 & 65.25 \\
\hline & Single & 139 & 34.75 \\
\hline \multirow{4}{*}{ Household Size } & $<3$ Persons & 36 & 9 \\
\hline & 3-5 Persons & 186 & 46.5 \\
\hline & 6-10 Persons & 159 & 39.75 \\
\hline & $>10$ Persons & 19 & 4.75 \\
\hline \multirow{7}{*}{ Average Monthly Household Income } & Less than $30,000 \mathrm{FCFA}$ & 95 & 23.8 \\
\hline & $30,000-50,000 \mathrm{FCFA}$ & 98 & 24.5 \\
\hline & $50,001-100,000 \mathrm{FCFA}$ & 60 & 15.0 \\
\hline & $100,001-200,000 \mathrm{FCFA}$ & 84 & 21.0 \\
\hline & $200,001-300,000$ FCFA & 48 & 12.0 \\
\hline & $300,001-400,000 \mathrm{FCFA}$ & 8 & 2.0 \\
\hline & $400,001-500,000$ FCFA & 4 & 1.0 \\
\hline
\end{tabular}

Source: Author, (2019).

From table 3 , it is observed that majority of the respondents $(54 \%)$ were males while the remaining $46 \%$ were females. This gender gap in favour of the males reflect the gender gap that exist among household heads on the in 
the North West Region as the culture of the people of North West Region gives more preference to the male as the household head and even in times of succession, the males are often given top priority. In relation to age, majority of the respondents $(44.5 \%)$ were of ages between 20 to 30 years. This is due to the fact that in most cases of very old parents, the eldest child was delegated to respond on behalf of the household. Going by educational attainments, majority $(42.75 \%)$ of them had secondary level of educational attainments, followed by tertiary $(38.25 \%)$ while primary was the least population, indicated by $19 \%$ of the respondents. Also, $65.25 \%$ of the respondents (Majority) were married people while $34.75 \%$ of them were singles among whom the majority of the households were made up of 3 to 5 persons even though some households $(4.75 \%)$ had more than 10 persons. In terms of the average monthly income, majority of the households (24.5\%) earn between 30,000 to 50,000 FCFA and the number of households drop almost continuously as we move to higher income brackets.

Table 4. Knowledge of Signs of Malaria

\begin{tabular}{llll}
\hline Knowledge about Signs of Malaria & Which sign (s) tell (s) you that someone is suffering from malaria & Frequency & Percent \\
\hline No & I don't know & 87 & 21.8 \\
& Body Weakness & 142 & 35.5 \\
& High temperature & 313 & 78.3 \\
& Headache & 150 & 37.5 \\
Yes & Vomiting & 93 & 23.3 \\
& Shivering & 176 & 44.0 \\
& Mouth bitterness/loss of appetite & 86 & 21.5 \\
& Joint pains & 145 & 36.3 \\
\hline
\end{tabular}

Source: Author, (2019).

Table 4 shows responses in relation to the respondents' knowledge of the signs of malaria and the findings reveal that $21.8 \%$ of the respondents were not able to know even one sign of malaria meaning that $88.2 \%$ of the respondents at least knew a sign of malaria this shows that despite the fact that majority of the respondent knew at least a sign of malaria, there is still knowledge gap on this issue which necessitates actions towards public health awareness in relation to malaria signs.

Table 5. Knowledge of the Causes of Malaria.

\begin{tabular}{llll}
\hline Knowledge of the cause of malaria & How is malaria caused & Frequency & Percent \\
\hline & I don't know & 10 & 2.4 \\
No & Overwork & 13 & 3.3 \\
& Witchcraft & 69 & 17.3 \\
Yes & Sub Total & 92 & 23.0 \\
\hline
\end{tabular}

Source: Author, (2019).

Table 5 summarises responses on the knowledge of the cause of malaria and the table depicts that $2.4 \%$ of the respondents indicated that they did not know the cause of malaria, 3.3\% of them attributed malaria to overwork and $17.3 \%$ of the respondents see malaria as being caused by witchcraft while $77 \%$ of the respondents clearly indicated that malaria is caused by mosquito bites. This also mean that despite the recurrence and proliferation of malaria in these communities, some people still do not know what causes malaria thereby jeopardising efforts towards eradication of malaria.

Table 6. Knowledge of Malaria Prevention Methods.

\begin{tabular}{|c|c|c|c|c|}
\hline Knowledge of malaria Prevention Methods & \multicolumn{2}{|c|}{ How best can malaria be prevented } & Frequency & Percent \\
\hline \multirow{5}{*}{ No } & \multicolumn{2}{|l|}{ I don't know } & 3 & 0.75 \\
\hline & \multicolumn{2}{|l|}{ Good personal hygiene } & 100 & 25.0 \\
\hline & \multicolumn{2}{|l|}{ Avoid excessive heat } & 73 & 18.3 \\
\hline & \multicolumn{2}{|l|}{ Can't be Prevented } & 1 & .3 \\
\hline & \multicolumn{2}{|l|}{ Eat Balanced Diet } & 20 & 5.0 \\
\hline \multirow{8}{*}{ Yes } & Type & Prevention Method & Frequency & Percent \\
\hline & \multirow{2}{*}{ Mosquito Eradication } & Clear buses around & 226 & 56.5 \\
\hline & & Use insects sprays & 68 & 17.0 \\
\hline & \multirow{4}{*}{ Prevention of Mosquito Bites } & Always close doors and windows & 122 & 30.5 \\
\hline & & Use repellents & 139 & 34.8 \\
\hline & & Fit Nets on Doors and Windows & 63 & 15.8 \\
\hline & & Sleep under an ITNs & 368 & 92.0 \\
\hline & Prophylactic Drugs & Taking anti-malaria drugs & 104 & 26.0 \\
\hline
\end{tabular}


In line with the respondents' knowledge of malaria prevention methods, $0.75 \%$ of the respondents indicated that they did not know how best malaria can be prevented, $25 \%$ of the respondents indicated good personal hygiene as the best way of preventing malaria, $18.3 \%$ of them indicated that malaria can be prevented by avoiding excessive heat, $0.3 \%$ of them said malaria can be prevented while $5 \%$ of them indicated that it can be preventing through eating balanced diet. Thus all of those who indicated the above measures did not know malaria prevention methods.

For the mosquito eradication measures, $56.6 \%$ of the respondents indicated that the best way to prevent malaria is to clear bushes around while $28.7 \%$ of them indicated creating a good drainage system as the best way to prevent malaria and $17 \%$ of them indicated the use of insect sprays to be the best practice to prevent malaria. Among the measures to prevent mosquito bites, $30.5 \%$ of the respondents indicated always closing doors and windows, $34.8 \%$ of them indicated the use of repellents, $15.8 \%$ of them indicated the fitting of nets on doors and windows (house modification) and $92 \%$ of them indicated sleeping under an ITNs while $26 \%$ of them indicated the frequent use of anti-malaria drugs. However, among the measures indicated, measures best known by the respondents are firstly the use of ITNs, secondly clearing of bushes around and thirdly the use of repellents (both local and biomedical).

Table 7. Malaria Prevention Method Predominantly Used.

\begin{tabular}{llll}
\hline Type of Malaria Prevention Method Predominantly Used & Modalities & Frequency & Percent \\
\hline None & & 124 & 31.0 \\
& Clear buses around & 180 & 45.0 \\
Mosquito Eradication & Good drainage system & 73 & 18.3 \\
& Use insects sprays & 23 & 5.8 \\
& Always close doors and windows & 78 & 19.5 \\
Prevention of Mosquito Bites & Fit Nets on Doors and Windows & 4 & 1.0 \\
& Use repellents & 49 & 12.3 \\
Prophylactic Drugs & Sleep under an ITNs & 279 & 69.8 \\
\hline
\end{tabular}

Source: Author, (2019).

Among the malaria prevention measures, those predominantly used are mostly the use of ITNs (69.8\%) clearing of bushes around (45\%), always closing of doors and windows $(19.5 \%)$ while the least used in the fitting of nets on doors and windows (house modification).

Table 8. Reasons for Choice of Malaria Prevention Option (s) Predominantly Used.

\begin{tabular}{lll}
\hline Reason & Frequency & Percent \\
\hline It is Free & 137 & 34.3 \\
It is Cheaper & 106 & 26.5 \\
It is readily Available & 77 & 19.3 \\
It is the One you Know & 83 & 20.8 \\
It is Effective & 5 & 1.3 \\
No Particular Reason & 25 & 6.3 \\
\hline
\end{tabular}

Source: Author, (2019).

Table 8 shows responses in relation to the reason for the choice of malaria prevention option predominantly adopted. The table reveals that most of the households choose malaria prevention options that is free $(34.3 \%)$, seconded by those that are cheaper $(26.5 \%)$, then those that choose because it is the one they know (20.8\%), those that choose because it is readily available $(19.3 \%)$, no particular reason $(6.3 \%)$ and lastly those that prefer an option because it is effective $(1.3 \%)$. This implies that most of the reasons for choice are economical availability in nature rather than effectiveness. This means that enhancing the economic abilities of the households can be an effective way of eradicating malaria.

Table 9. Summary of Descriptive Analysis.

\begin{tabular}{|c|c|c|c|c|c|c|}
\hline Variable & Modalities & Obs & Mean & Std. Dev. & Min & Max \\
\hline \multirow[t]{2}{*}{ nprev } & Count & 400 & 1.908805 & 1.238064 & 0 & 8 \\
\hline & Prophylactic Drugs & 400 & .0025 & .05 & 0 & 1 \\
\hline \multirow[t]{2}{*}{ prev } & Prevention of Bites & 400 & .4625 & .4992162 & 0 & 1 \\
\hline & Mosquito Eradication & 400 & .4475 & .4978588 & 0 & 1 \\
\hline cbmp & Numerical & 400 & 37.57367 & 6.198891 & 33 & 55 \\
\hline know_sign & Dummy & 400 & .315364 & .157412 & 0 & 1 \\
\hline know_cause & Dummy & 400 & .6895777 & .4627705 & 0 & 1 \\
\hline age & Numerical & 400 & 35.2372 & 19.08124 & 11 & 90 \\
\hline Ms_married & Dummy & 400 & .6522911 & .47635 & 0 & 1 \\
\hline
\end{tabular}




\begin{tabular}{llllll}
\hline Variable & Modalities & Obs & Mean & Std. Dev. & Min \\
\hline hhs & Count & 400 & 7.451033 & 4.987587 & 1 \\
cost_prev & FCFA & 400 & 2833.336 & 3412.412 & 0 \\
income & FCFA & 400 & 144281.2 & 119185.1 & 30000 \\
& Secondary & 400 & .4514825 & .4977523 & 0 \\
Educ & Tertiary & 400 & .3602875 & .4801916 & 0 \\
& Dummy & 400 & .6545373 & .4756257 & 0 \\
emp & Dummy & 400 & .4636119 & .4987862 & 0 \\
tpr_rural & & 1 & 1 & 1 \\
\hline
\end{tabular}

Source: Author, (2019).

Table 9 reveals that there were in total 8 malaria prevention methods identified and used by the households in the study area and the mean of 1.9 shows that on average, each household adopted 2 malaria prevention options among the 8 options and in terms of the 3 categories of prevention options adopted, the mean of reveals that cumulatively only less than $1 \%(0.25 \%)$ of them adopted the use of anti-malaria (prophylactic) drugs, while $46.25 \%$ (the majority) adopted options that prevent mosquito bites, most especially sleeping under ITNs as revealed by table 6 . also, $44.75 \%$ of the respondents adopted measures to eradicate mosquitoes meaning that the remaining about $8.75 \%$ did not adopt any malaria prevention option.

For other demographic information considered as variables in this study, $54.4 \%$ of the household heads were males and the household heads had an average age of 35.2 years with the youngest being 11years and the oldest 90years. Among them, $65.2 \%$ were married and the average household size was about 7 persons with the smallest households having only one person and the largest having up to 30 individuals.
In terms of cost, the maximum cost of prevention of malaria was identified to be about 20,000 FCFA with some prevention options even costing nothing with an average cost of prevention being about 2,800 FCFA. Also, on the part of income, the average household income indicated was 144,281 FCFA with a minimum of 30,000 FCFA and a maximum of up to 600,000 FCFA.

Furthermore, in relation to the highest educational attainments of the household heads, the responses reveal that about $45 \%$ of the household heads were secondary school leavers, about $36 \%$ of them tertiary education meaning the remaining about $19 \%$ of them had the primary level of education. Also, about $65.5 \%$ of the household heads were employed meaning $44.5 \%$ were unemployed. In line with the type of place of residence, about $46.4 \%$ of the households were in the rural areas revealing that 53.6 of them were in urban settings. This is however, due to the fact that most rural areas were not that accessible as previewed due to the current socio-political crisis being faced by our study area.

Table 10. Pairwise Correlation Matrix.

\begin{tabular}{|c|c|c|c|c|c|c|c|c|c|c|c|c|}
\hline & cbmp & $\begin{array}{l}\text { Know } \\
\text { sign }\end{array}$ & $\begin{array}{l}\text { Know } \\
\text { cause }\end{array}$ & $\operatorname{sex}$ & age & ms & hhs & $\begin{array}{l}\text { Cost } \\
\text { prev }\end{array}$ & income & educ & emp & $\begin{array}{l}\text { Tpr } \\
\text { rural }\end{array}$ \\
\hline cbmp & 1.0000 & & & & & & & & & & & \\
\hline know_sign & -0.0926 & 1.0000 & & & & & & & & & & \\
\hline know_cause & 0.2395 & -0.0982 & 1.0000 & & & & & & & & & \\
\hline $\operatorname{sex}$ & 0.1079 & 0.0512 & -0.0640 & 1.0000 & & & & & & & & \\
\hline age & 0.0541 & 0.0494 & -0.3648 & 0.3772 & 1.0000 & & & & & & & \\
\hline $\mathrm{ms}$ & 0.1546 & 0.1509 & -0.1881 & 0.2842 & 0.5293 & 1.0000 & & & & & & \\
\hline hhs & -0.1268 & -0.0114 & -0.3284 & 0.2040 & 0.6877 & 0.1882 & 1.0000 & & & & & \\
\hline cost_prev & -0.1443 & 0.0523 & -0.2687 & -0.0022 & 0.1772 & 0.1123 & 0.1213 & 1.0000 & & & & \\
\hline income & -0.1788 & 0.1355 & -0.1783 & 0.1860 & 0.2701 & 0.2051 & 0.2100 & 0.1462 & 1.0000 & & & \\
\hline educ & 0.0659 & 0.3035 & 0.0942 & 0.0836 & -0.0174 & 0.1613 & -0.1061 & -0.0940 & 0.2716 & 1.0000 & & \\
\hline emp & -0.0590 & -0.0282 & 0.0251 & 0.0003 & -0.0604 & 0.2492 & -0.2177 & -0.0156 & 0.0784 & 0.0306 & 1.0000 & \\
\hline tpr_rural & -0.1862 & -0.1716 & -0.1220 & -0.0547 & 0.0452 & 0.0300 & 0.1490 & -0.0026 & -0.1669 & -0.4146 & 0.2435 & 1.0000 \\
\hline
\end{tabular}

Source: Author, (2019).

Table 10 presents the correlation matrix table and it shows the relationships between pairs of the independent variables. This was to check whether there are very strong relationships between pairs of the independent variables which may indicate the presence of multicollinearity. The table reveals no very strong relationships between the independent variables leading us to conclude that the problem of multicollinearity does not exist among our variables. This serves as a pre-test and thus validates our model for further analysis.

In order to examine the socioeconomic determinants of malaria prevention behaviour of households, three different methods (OLS, Poisson and Ordered Logit) were used. These different methods were used to check the consistency of the results using the different methods, hence the robustness of the methodologies and results. Using the number of malaria prevention options adopted (which is a count variable) as the dependent variable, OLS and Poisson regression were used while Ordered Logit regression was used in the case where malaria prevention options were grouped and ordered according to their scope of coverage. Table 11 presents the findings on the socioeconomic determinants of malaria prevention behaviours. 
Table 11. Results on the Socioeconomic Determinants of Malaria Prevention Behaviours.

\begin{tabular}{|c|c|c|c|}
\hline \multirow{2}{*}{ VARIABLES } & (OLS) & (Poisson) & (Ologit) \\
\hline & nprev & nprev & prev \\
\hline \multirow[t]{2}{*}{ cbmp } & $0.0335^{* * *}$ & $0.0149 * * *$ & $0.0514 * * *$ \\
\hline & $(0.00650)$ & $(0.00363)$ & $(0.0116)$ \\
\hline \multirow{2}{*}{ know_sign } & $0.163^{* * *}$ & $0.0744 * * *$ & 0.0822 \\
\hline & $(0.0309)$ & $(0.0178)$ & $(0.0529)$ \\
\hline \multirow[t]{2}{*}{ know_cause } & $0.254 * * *$ & $0.117 * * *$ & $0.805 * * *$ \\
\hline & $(0.0733)$ & $(0.0428)$ & $(0.126)$ \\
\hline \multirow[t]{2}{*}{ sex } & 0.0329 & 0.0175 & -0.0672 \\
\hline & $(0.0711)$ & $(0.0418)$ & $(0.120)$ \\
\hline \multirow[t]{2}{*}{ age } & $0.0338 * * *$ & $0.0152 * * *$ & $0.0538 * * *$ \\
\hline & $(0.00296)$ & $(0.00167)$ & $(0.00574)$ \\
\hline \multirow[t]{2}{*}{$\mathrm{ms}$} & $-0.787 * * *$ & $-0.370 * * *$ & $-0.430 * * *$ \\
\hline & $(0.0918)$ & $(0.0544)$ & $(0.155)$ \\
\hline \multirow[t]{2}{*}{ hhs } & $-0.0618 * * *$ & $-0.0264 * * *$ & $-0.0548 * * *$ \\
\hline & $(0.00939)$ & $(0.00527)$ & $(0.0184)$ \\
\hline \multirow[t]{2}{*}{ lcost_prev } & $-0.158 * * *$ & $-0.0770 * * *$ & $0.318 * * *$ \\
\hline & $(0.0340)$ & $(0.0215)$ & $(0.0573)$ \\
\hline \multirow[t]{2}{*}{ lincome } & 0.0268 & 0.0249 & $0.176^{* * *}$ \\
\hline & $(0.0404)$ & $(0.0245)$ & $(0.0677)$ \\
\hline \multirow[t]{2}{*}{ educ_secondary } & $0.244 * * *$ & $0.135 * *$ & $0.630 * * *$ \\
\hline & $(0.0943)$ & $(0.0582)$ & $(0.166)$ \\
\hline \multirow[t]{2}{*}{ educ_tertiary } & $0.340 * * *$ & $0.186 * * *$ & $0.451^{* *}$ \\
\hline & $(0.110)$ & $(0.0666)$ & $(0.189)$ \\
\hline \multirow[t]{2}{*}{ emp } & $0.143^{*}$ & $0.0823^{*}$ & $-0.521 * * *$ \\
\hline & $(0.0780)$ & $(0.0448)$ & $(0.136)$ \\
\hline \multirow[t]{2}{*}{ tpr_rural } & -0.0644 & -0.0385 & -0.203 \\
\hline & $(0.0720)$ & $(0.0416)$ & $(0.125)$ \\
\hline Constant cut 1 & & & $\begin{array}{l}1.387 \\
(1.034)\end{array}$ \\
\hline \multirow[t]{2}{*}{ Constant cut 2} & & & 1.451 \\
\hline & & & $(1.034)$ \\
\hline \multirow[t]{2}{*}{ Constant cut3 } & & & $4.256 * * *$ \\
\hline & & & $(1.041)$ \\
\hline \multirow[t]{2}{*}{ Constant } & -0.829 & -0.536 & \\
\hline & $(0.615)$ & $(0.368)$ & \\
\hline Observations & 400 & 400 & 400 \\
\hline R-squared & Adjusted $=0.1797$ & Pseudo $=0.0447$ & Pseudo $=0.1014$ \\
\hline
\end{tabular}

Standard errors in parentheses.

$* * * \mathrm{p}<0.01, * * \mathrm{p}<0.05, * \mathrm{p}<0.1$.

Source: Author, (2019).

The findings from table 11 reveal that, controlling for other effects, a percentage increase in the community based malaria prevalence increases the number of malaria prevention options adopted by households in such areas. This is true for both the OLS and the Poisson regression results and it is in line with the findings of [22]. The findings specifically show that a percentage increase in community based malaria prevalence results to 0.0335 increase in the number of malaria prevention options adopted meaning a $30 \%$ increase in community based malaria prevalence can lead to the adoption of one addition malaria prevention option. The Poisson regression results reveal that if community based malaria prevalence were to increase by $1 \%$, the difference in the logs of expected counts (number of malaria prevention options adopted) would be expected to increase by 0.0149 unit, while holding the other variables in the model constant. The ordered logit results reveal that households in communities with higher community based malaria prevalence are less likely to adopt malaria prevention options that are more holistic. That is such households rather prefer more individualised malaria prevention options over more holistic. The finding specifically shows that a one percent increase in community based malaria prevalence would result in a 0.0514 unit decrease in the ordered log-odds of choosing a more holistic malaria prevention option holding the other variables in the model constant. The effect of community based malaria prevalence on the malaria prevention behaviour is significant at $1 \%$ level of significance for all the three analytical techniques used. This implies that malaria prevention behaviour is strongly influenced by the community based malaria prevalence.

Secondly, in relation to knowledge about signs of malaria, having knowledge of the signs of malaria compared to not having increases the number of malaria prevention options adopted by household since knowing the signs of malaria compared to not knowing increases the number of malaria prevention options adopted by 0.163 units and those who know the signs of malaria are expected to adopt 1.493 times 
more malaria prevention options compared to those who do not know the signs. The positive effect is also in line with the findings of earlier researchers such as [22] in Kenya, [26] in Tanzania and [13] in Rural areas of North West Region of Cameroon. Also, the ordered logit for those who know the signs of malaria adopting a more holistic malaria prevention option is 0.0822 more than those who do not know the signs of malaria when the other variables in the model are held constant. The effect of knowledge of signs of malaria is significant at $1 \%$ for OLS and Poisson regression results showing that knowledge of the sign of malaria significantly affect the number of malaria prevention options adopted but does not significantly affect the types of malaria prevention options adopted.

Also, for knowledge of the cause of malaria, having knowledge of the cause of malaria compared to not having increases the number of malaria prevention options adopted by household. This is because knowing the cause of malaria compared to not knowing increases the number of malaria prevention options adopted by 0.254 units and those who know the cause of malaria are expected to adopt 0.117 times more malaria prevention options compared to those who do not know the cause which is again in line with the findings of $[22,26,13]$. Also, the ordered logit for those who know the cause of malaria adopting a more holistic malaria prevention option is 0.805 more than those who do not know the cause of malaria when the other variables in the model are held constant. The effect of knowledge of the cause of malaria is significant at $1 \%$ for all the three results showing that knowledge of the cause of malaria significantly affect the number and the type of malaria prevention options adopted.

Furthermore, male household heads are more likely to adopt more but less holistic malaria prevention options compared to their female counterparts since male household heads adopt 0.0329 units more malaria prevention options and are expected to adopt 0.0175 times more malaria prevention options but have 0.0672 less ordered log odds of choosing more holistic malaria prevention options compared to their female counterparts. The effect of gender of household head is however insignificant revealing that gender of household head does not significantly affect malaria prevention behaviour of household be it in terms of number or type of malaria prevention options adopted.

More so, the findings in table 11 reveal that, controlling for other effects, a year increase in the age of household head increases the number and type of malaria prevention options adopted by households. This is true for both number of malaria prevention options adopted (OLS and Poisson regression) and type of malaria prevention options adopted (Ordered Logit results). This is in line with the findings of [25] among pregnant women in Kenya, [26] using data from the Demographic Health Survey for Tanzania HIV/AIDs and the Malaria Indicator Survey 2011-2012 in a cross-sectional design. The findings specifically show that a year increase in age of household head results to 0.0338 units increase in the number of malaria prevention options adopted. The Poisson regression results reveal that if household head's age were to increase by 1year, the difference in the logs of expected counts (number of malaria prevention options adopted) would be expected to increase by 0.0152 unit, while holding the other variables in the model constant. The ordered logit results reveal that older household heads are more likely to adopt malaria prevention options that are more holistic than younger ones. That is older household heads prefer more holistic malaria prevention options over more individualised ones. The finding specifically shows that a 1year increase in the age of a household head would result in a 0.0538 unit increase in the ordered log-odds of choosing a holistic malaria prevention option holding the other variables in the model constant. The effect of age of household head on the malaria prevention behaviour is significant at $1 \%$ level of significance for all the three analytical techniques used. This implies that age is a social factor that significantly determine malaria prevention behaviour both in terms of the number and type of malaria prevention options adopted. Furthermore, married household heads are rather less likely to adopt more and holistic malaria prevention options compared to household heads that are single which is contrary to our expectations and it is also in sharp contrast with the findings of $[27,13]$ since marred household heads adopt 0.787 units less malaria prevention options and are expected to adopt 0.370 times less malaria prevention options than household heads that are not married. Married household heads also have 0.430 less ordered log odds of choosing more holistic malaria prevention options compared to their unmarried counterparts. The effect of marital status of household head is significant at $1 \%$ level of significance for all the three results revealing that marital status of household head is a social factor that significantly affects malaria prevention behaviour of household both in terms of number and type of malaria prevention options adopted.

Also, the findings in table 11 reveal that, controlling for other effects, increase in household size decreases the number and type of malaria prevention options adopted by households which is contrary to the findings of [13]. This is true for both number of malaria prevention options adopted (OLS and Poisson regression) and type of malaria prevention options adopted (Ordered Logit results). The findings specifically show that a one person increase in household size results to 0.0618 units decrease in the number of malaria prevention options adopted and the household size were to increase by one person, the difference in the logs of expected counts (number of malaria prevention options adopted) would be expected to decrease by 0.0264 unit, while holding the other variables in the model constant. The ordered logit results reveal that larger households are less likely to adopt malaria prevention options that are more holistic than smaller ones. That is larger households prefer more individualised malaria prevention options over more holistic ones. The finding specifically shows that a one person increase in the household size would result in a 0.0548 unit decrease in the ordered log odds of choosing a holistic malaria prevention option holding the other variables in the model constant. The effect of household size on the malaria prevention behaviour 
is significant at $1 \%$ level of significance for all the three analytical techniques used. This implies that household size is a social factor that significantly determine malaria prevention behaviour both in terms of the number and type of malaria prevention options adopted.

Also, cost of prevention negatively affect the number and type of malaria prevention options adopted by households. The findings specifically show that a $1 \%$ increase in cost of malaria prevention results to 0.158 units fall in the number of malaria prevention options adopted and if cost of prevention were to increase by $1 \%$, the difference in the logs of expected counts (number of malaria prevention options adopted) would be expected to decrease by 0.0770 units, while holding the other variables in the model constant. The ordered logit results reveal that a $1 \%$ increase in the cost of prevention would result in a 0.318 unit increase in the ordered log odds of choosing a holistic malaria prevention option holding the other variables in the model constant. The effect of cost of malaria prevention on the malaria prevention behaviour is significant at $1 \%$ level of significance for all the three analytical techniques used. This implies that cost of prevention of malaria is an economic factor that significantly determine malaria prevention behaviour both in terms of the number and type of malaria prevention options adopted.

Furthermore, income of households positively affect the number of malaria prevention options adopted by households and also increases the likelihood of households choosing a holistic malaria prevention options over individualised ones. This is as expected and corroborate with the findings of [24, 13]. The findings specifically show that a $1 \%$ increase in households monthly income will lead to 0.0268 units increase in the number of malaria prevention options adopted and if households monthly income were to increase by $1 \%$, the difference in the logs of expected counts (number of malaria prevention options adopted) would be expected to increase by 0.0249 units, while holding the other variables in the model constant. The ordered logit results reveal that a $1 \%$ increase in the monthly income of households would result in a 0.176 unit increase in the ordered log odds of choosing a holistic malaria prevention option holding the other variables in the model constant. The effect of household monthly income on the malaria prevention behaviour is insignificant for number of malaria prevention options adopted but significant at $1 \%$ level of significance for the type of malaria prevention options adopted. This implies that household monthly income is an economic factor that significantly determine malaria prevention behaviour in terms of the type of malaria prevention options adopted.

Moreover, educational attainment of household heads positively affect the number and type of malaria prevention options adopted. This means that more educated household heads are more likely to adopt more and holistic malaria prevention options compared to their less educated counterparts. The findings show that compared to households headed by persons with primary educational attainments, household heads with secondary level of educational attainments adopt 0.244 units more of malaria prevention options, and are expected to adopt 0.135 times more malaria prevention options and have 0.0672 higher ordered log odds of choosing more holistic malaria prevention options. For the results comparing tertiary with primary education, the findings suggest that household heads with tertiary level of educational attainments adopt 0.340 units more of malaria prevention options, and are expected to adopt 0.186 times more malaria prevention options and have 0.451 higher ordered $\log$ odds of choosing more holistic malaria prevention options compared to household heads with primary level of educational attainments. The positive effect is just as expected and the findings tie with those of [22, 24, $28,13,27]$.

Furthermore, employed household heads are more likely to adopt more but less holistic malaria prevention options compared to their unemployed counterparts since employed household heads adopt 0.143 units more malaria prevention options and are expected to adopt 0.0823 times more malaria prevention options as expected and it is in line with the findings of [24] but have 0.521 less ordered log odds of choosing more holistic malaria prevention options compared to their unemployed counterparts. The effect of employment status of household head is significant at $10 \%$ for the number of malaria prevention options and significant at $1 \%$ level of significance for the type of malaria prevention option adopted revealing that employment status of household head is a socioeconomic factor that significantly affect malaria prevention behaviour of household both in terms of number or type of malaria prevention options adopted.

For the type of place of residence, rural dwellers are less likely to adopt more and holistic malaria prevention options than urban dwellers. This means that people living in the rural areas adopt fewer and individualised malaria prevention options compared to those living in urban areas. The effect of type of place of residence is however, insignificant for all the results and thus type of place of residence does not significantly determine the malaria prevention behaviour of households in the North West Region of Cameroon.

The constant cut1 shows that households that had a value of 1.387 or less on the underlying latent variable that gave rise to our type of malaria prevention option adopted would be classified as adopting none of the types of malaria prevention options given that all the coefficients of predictor variables were zero. The constant cut 2 shows that households that had a value greater than 1.387 but less than 1.451 on the underlying latent variable that gave rise to our type of malaria prevention option adopted would be classified as adopting individualized prevention option given that all the coefficients of predictor variables were zero. Households that had a value between 1.451 and 4.256 on the underlying latent variable would be classified as adopting measure to prevent mosquito bites while households that had values of 4.256 and above are classifying as those adopting holistic malaria prevention measures assuming that the effects of all the predictors are nullified.

Socioeconomic factors used in this study are able to explain only $17.97 \%$ of malaria prevention behaviour of 
households in the North West Regions meaning that there are many other factors that determine malaria prevention of households that are not socioeconomic in nature. Also, for overall significance of the results, the F-statistics of 25.97 and its P-value less than 0.01 for OLS model, the LR ChiSquare value of 219.25 with its P-value less than 0.01 for the Poisson regression analysis and LR Chi-Square of 277.28 with its P-value less than 0.01 all reveal that the results are overall significant at $1 \%$ level meaning that our findings are $99 \%$ reliable.

Table 12. Variance Inflation Factor Test for Multicollinearity.

\begin{tabular}{lll}
\hline Variable & VIF & $\mathbf{1 / V I F}$ \\
\hline cbmp & 1.21 & 0.825238 \\
know_sign & 1.20 & 0.836141 \\
know_cause & 1.34 & 0.744014 \\
sex & 1.33 & 0.752816 \\
age & 4.04 & 0.247415 \\
ms & 2.02 & 0.496165 \\
hhs & 3.10 & 0.322909 \\
lcost_prev & 1.09 & 0.916988 \\
lincome & 1.41 & 0.706918 \\
Educ_Secondary & 2.34 & 0.426483 \\
Educ_Tertiary & 2.72 & 0.367256 \\
emp & 1.41 & 0.707683 \\
tpr_rural & 1.37 & 0.730654 \\
Mean VIF & 1.89 & \\
\hline
\end{tabular}

Source: Author, (2019).

The VIF results presented in table 12 above reveals a mean VIF of 1.89 which is less than the bench mark VIF of greater than or equals to 2.5 which means that our analyses are void of Multicollinearity which validates the results estimated.

Table 13. Breusch-Pagan / Cook-Weisberg test for Heteroskedasticity.

Ho: Constant variance

Variables: fitted values of nprev

chi2 (1) $=1.95$

Prob $>$ chi $2=0.5654$

Source: Author, (2019). Table 13 shows the Breusch-Pagan / Cook-Weisberg test for Heteroskedasticity with a null hypothesis of constant variance (Homoskedasticity) meaning the alternative hypothesis is no constant variance (Heteroskedasticity). The results predict a Chi-Square value of 1.95 with its $\mathrm{p}$-value greater than even 0.10 . This implies that the test is insignificant and thus we fail to reject the null hypothesis thereby rejecting the alternative. This implies that our results are homoscedastic in nature which further validates the findings of this study.

\section{Conclusion and Policy Recommendations}

The findings of the study presents some knowledge gap in the cause and signs of malaria since to some even have a myth/belief about malaria that it is caused by witchcraft and hence cannot be prevented. This cause some of such household to results to less advance and less effective malaria treatment options during episodes of malaria illness which influences their return rate to good health thereby compromising their welfare.

Also, there is a knowledge in relation to the possible available malaria prevention options as some of them indicated good personal hygiene, avoid excessive heat, eating of balanced diet as malaria prevention options and even to a person, can't be prevented.

The findings also suggest that the most frequently used method of malaria prevention and those the prevent mosquito bite; most especially the use of ITNS instead of those that even stop the breeding of mosquito which are more sustainable. The malaria treatment choice most frequently preferred is the public health care and their reasons for adopting the malaria prevention and treatment choices they adopt are mostly associated to cost of the prevention and treatment as they mostly go in for the inexpensive ones.

The findings on the socioeconomic determinants of malaria prevention behaviour of households reveal that community based malaria prevalence, knowledge of malaria signs, knowledge of malaria cause, age of household heads, marital status of household heads, household size, cost of malaria prevention, household monthly income, education attainment of the household head and employment status of the household head are all socioeconomic factors that determine malaria prevention options adoption by households in the North West Region.

From the above counts, this study strongly recommends that in order to improve upon malaria prevention efforts, households should be well sensitized on the causes, signs and prevention options of malaria. This can be achieved through sensitization campaigns; the creation of community-based malaria control committees and sponsored media programs. Such may target especially male household heads, single parents and less educated parents and emphases should be placed on the more holistic and sustainable malaria prevention strategies. Thus the government needs to increase its current budget on health by about $42 \%$ to meet up with this target. This is equally applicable to private health care institutions.

Special tax fund against malaria prevention at local council areas needs to be put in place to meet the needs of the needy. Also, households should be empowered through creating more income generating activities for households especially women empowerment activities which may raise the income of households, thereby enabling them to afford more and holistic approaches to malaria preventions and also seek for the best possible treatment options in the advent of malaria.

Also, improving the formal education of parents can improve on their malaria prevention and treatment seeking behaviours. This can be achieved by creating more and flexible learning facilities and further subsidizing education, especially for adults. In this case, education should not only be seen for investment but also for consumption, selfdevelopment, and national awareness and for selfactualization.

From the findings, it is clear those communal efforts for the prevention of malaria may be very effective as it may help eradicate mosquitoes in the community as a whole. Thus community works and communal behaviours are recommended to households instead of individualistic behaviours which don't have any lasting effect on malaria 
prevention.

Further distribution of free ITNs and other facilities to control malaria such as insecticides and anti-malaria drugs should be intensified not only to pregnant women but at least each household in the North West region in particular and Cameroon at large.

\section{References}

[1] Packard, R. (2008). The Making of a Tropical Disease: A Short History of Malaria. Johns Hopkins University Press.

[2] Devarajan, B. C., \& Gersbach, S. H. (2006). The long-run economic costs of AIDS: a model and an application to South Africa. World Bank Economic Review, 20, 55-89.

[3] Gallup, J. L., \& Sachs, J. D. (2001). The economic burden of malaria. American Journal of Tropical Medicine \& Hygiene, 64 (supp 1), 85-96.

[4] Artadi, E., \& Sala-I-Martin, X. (2003). The economic tragedy of the XXth Century: Growth in Africa. NBER Working Paper 9865. National Bureau of Economic Research. Massachusetts, USA: Cambridge.

[5] Ngum, J. W., Ongolo-Zogo, P., Tallah, E., Leke, R., \& Mbacham, W. (2010). Policy Brief on scaling up malaria control interventions in Cameroon. Executive summary.

[6] Kouznetsov, R. L. (1977). Malaria control by application of indoor spraying of residual insecticides in tropical Africa and its impact on community health. Tropical doctor, 7 (2), 81-91.

[7] Mbenda, H. G. N., Awasthi, G., Singh, P. K., Gouado, I., \& Das, A. (2014). Does malaria epidemiology project Cameroon as 'Africa in miniature'?. Journal of biosciences, 39 (4), 727-738.

[8] Ministry of Public Heaalth (MoH), (2007). National Malaria Control Programme, NMCP 2007-2010. Yaounde, Cameroon.

[9] Ongolo-Zogo, P., \& Bonono, R. C. (2010). Policy brief on improving access to artemisinin-based combination therapies for malaria in Cameroon. International Journal of Technology Assessment in Health Care, 26 (2), 237-241.

[10] Ministry of Public Heaalth (MoH), (2015). National Strategic Plan (NSP) for malaria control for 2014-2018. Yaounde, Cameroon: Cameroon Government, Ministry of Public Health.

[11] USAID. (2017). President's Malaria Initiative Cameroon Malaria Operational Plan FY 2017. USA: Center for Disease Control Prevention.

[12] Tchekountouo, O. \& Col. (2016). Rapport annuel des activités de lutte contre le paludisme dans le Nord-Ouest. Bamenda: Regional Malaria Control Unit, North West Regional Delegation of Public Health.

[13] Nfor, O. N, Njimanted G. F, Yakum I. M, Fozoh I. A. (2019) Malaria Preventive Behaviour among Rural Households in the North West Region of Cameroon. J Trop Dis 7: 312. doi: 10.4172/2329-891X.1000312.

[14] Killeen, G. F., Mackenzie, F. E., Foy, B. D., Schiestelin, C., Billingsley, P., \& Beier, J. C. (2000). A simplified model for predicting malaria entomologic inoculation rates based on entomologic and parasitologic parameters relevant to control. Am. J. Prop. Med Hyg, 535-544.
[15] Arrow, K. J., Panosian, C. B., \& Gelband, H. (2004). Saving lives, buying time: Economics of malaria drugs in an age of resistance. Washington, DC: The national academies press.

[16] Manana, S. (2016). Public health challenges facing malaria elimination in developing countries: a review of expert opinions.

[17] Sotiroff-Junker. (1978). A Bibliography on the Behavioural, Social and Economic Aspects of Malaria and Its Control. WHO publication.

[18] Worrall, E., Basu, S., \& Hanson, K. ( 2002). The relationship between socio-economic status and malaria: a review of the literature. London: Ensuring that malaria control interventions reach the poor.

[19] Heggenhougen, H. K., Hackethal, V., \& Vivek, P. (2003). The behavioural and social aspects of malaria and its control: An introduction and annotated bibliography. Social, Economic and Behavioural (SEB) Research.

[20] Worrall, E., Basu, S., \& Hanson, K. (2005). Is malaria a disease of poverty? A review of the literature. Tropical medicine \& international health: TM \& IH, 10 (10), 10471059 .

[21] Ricci, F. (2012). Social Implications of Malaria and their Relations with Poverty. Mediterranean Journal Of Hematology And Infectious Diseases, 2035-3006.

[22] Diiro, G. M., Affognon, H. D., Muriithi, B. W., \& Wanja, S. K. (2016). The Role of Gender on Malaria Preventive Behaviour among Rural Households in Kenya. Malaria Journal.

[23] Goodman, C., Hanson, K., Mills, A., Wiseman, V., \& Worrall, E. (2003). The Economics Of Malaria And Its Control. Paper for the WHO/TDR Scientific Working Group on Malaria.

[24] Dako-Gyeke, M., \& Kofie, H. M. (2015). Factors Influencing Prevention and Control of Malaria among Pregnant Women Resident in Urban Slums, Southern Ghana. African Journal of Reproductive Health.

[25] Choonara, S., Odimegwu, C. O., \& Elwange, B. C. (2015). Factors influencing the usage of different types of malaria prevention. African Health Sciences, 15 (2).

[26] Derjew, E. T. (2017). Knowledge of Malaria Infection and Treatment-Seeking Behavior Among Tanzanian Pregnant Women. Epidemiology Commons.

[27] Tobin-West, C. I., \& Kanu, E. N. (2016). Factors Influencing the Use of Malaria Prevention Methods Among Women of Reproductive Age in Peri-urban Communities of Port Harcourt City, Nigeria. Nigerian Postgraduate Medical Journal.

[28] Mbako, J. D., Barffo, D., Nuotol, R. K., \& Alebsehehy, R. (2017). Enhancing Malaria Prevention in Cameroon Through Community Participation: An in-Depth Review. Central African Journal of Public Health, 3 (6), 97-109.

[29] Inhorn, M. C., \& Brown, P. J. (1990). The anthropology of infectious disease. Annual review of Anthropology, 19 (1), 89-117.

[30] MacCormack, C. P. (1984). Human ecology and behaviour in malaria control in tropical Africa. Bulletin of the World Health Organization, 62 (Suppl), 81. 
[31] Link, B. G., \& Phelan, J. (1995). Social conditions as fundamental causes of disease. Journal of health and social behavior, 80-94.

[32] Farmer, K. C. (1999). Methods for measuring and monitoring medication regimen adherence in clinical trials and clinical practice. Clinical therapeutics, 21 (6), 1074-1090.

[33] Paul, B. D. (1955). Health, culture, and community. Russell Sage Foundation.

[34] Polgar, S. (1962). Health and human behavior: areas of interest common to the social and medical sciences. Current Anthropology, 3 (2), 159-205.

[35] Etkin, D. A. (1991). Break-up in Hudson Bay: its sensitivity to air temperatures and implications for climate warming. Climatological Bulletin, 25 (1), 21-34.

[36] Onwujekwe, O., Uzochukwu, B., Eze, S., Obikeze, E., Okoli, C., \& Ochonma, O. (2008). Improving equity in malaria treatment: relationship of socio-economic status with health seeking as well as with perceptions of ease of using the services of different providers for the treatment of malaria in Nigeria. Malaria Journal, 7 (1), 5.

[37] Owumi, B., \& Raji, S. O. (2013). Socio-cultural determinants of maternal health care seeking behaviour in seme side of Benin Republic.
[38] WHO. (2015). World malaria report. Geneva: Available online accessed from: http://apps.who.int/iris/bitstram/10665/200028/1/9789241565 158_eng.pdf.

[39] Cochran, W. G. (1963). Sampling Techniques,. (2. Éd.) New York: John Wiley and Sons, Inc.

[40] Njimanted, G. F., Nfor, O. N., Yakum, I. M., \& Mobit, M. O. (2017). Households' Choices of Healthcare Services in the North West Region of Cameroon. Journal Of The Cameroon Academy Of Sciences, Vol. 14 No. 1, 41-55. doi: https://dx.doi.org/10.4314/jcas.v14i1.4

[41] Sahn, D. E., Younger, S. D., \& Genicot, G. (2003). The Demand for Health Care Services in Rural Tanzania. Oxford Bulletin of Economics and Statistics, 65 (2), 0305-9049.

[42] Gertler, P., \& Van der Gaag, J. (1990). Willingness to Pay for Medical Care: Evidence from Two Developing Countries. Baltimore, Maryland: Johns Hopkins University Press.

[43] Solís, D., Bravo-Ureta, B. E., \& Quiroga, R. E. (2007). Soil conservation and technical efficiency among hillside farmers in Central America: a switching regression model. Aust $\mathbf{J}$ Agric Resour Econ, 491-510. 